Washington University in St. Louis

Washington University Open Scholarship

Biology Faculty Publications \& Presentations

Biology

$12-2020$

\title{
Charged pore-lining residues are required for normal channel kinetics in the eukaryotic mechanosensitive ion channel MSL1
}

Angela M. Schlegel

Washington University in St. Louis

Elizabeth S. Haswell

Washington University in St. Louis

Follow this and additional works at: https://openscholarship.wustl.edu/bio_facpubs

Part of the Biology Commons

\section{Recommended Citation}

Schlegel, Angela M. and Haswell, Elizabeth S., "Charged pore-lining residues are required for normal channel kinetics in the eukaryotic mechanosensitive ion channel MSL1" (2020). Biology Faculty Publications \& Presentations. 243.

https://openscholarship.wustl.edu/bio_facpubs/243

This Article is brought to you for free and open access by the Biology at Washington University Open Scholarship. It has been accepted for inclusion in Biology Faculty Publications \& Presentations by an authorized administrator of Washington University Open Scholarship. For more information, please contact digital@wumail.wustl.edu. 


\section{Channels}

\section{Charged pore-lining residues are required for normal channel kinetics in the eukaryotic mechanosensitive ion channel MSL1}

\section{Angela M. Schlegel \& Elizabeth S. Haswell}

To cite this article: Angela M. Schlegel \& Elizabeth S. Haswell (2020) Charged pore-lining residues are required for normal channel kinetics in the eukaryotic mechanosensitive ion channel MSL1, Channels, 14:1, 310-325, DOI: 10.1080/19336950.2020.1818509

To link to this article: https://doi.org/10.1080/19336950.2020.1818509
(C) 2020 The Author(s). Published by Informa UK Limited, trading as Taylor \& Francis Group.

\section{to}

View supplementary material $\sqsubset$

\section{曲 Published online: 29 Sep 2020.}

\section{Submit your article to this journal $\sqrt{3}$}

\section{山ll Article views: 244}

Q View related articles $\sqsubset$

View Crossmark data 


\title{
Charged pore-lining residues are required for normal channel kinetics in the eukaryotic mechanosensitive ion channel MSL1
}

\author{
Angela M. Schlegel $\mathbb{1}^{\mathrm{a}, \mathrm{b}}$ and Elizabeth S. Haswell ${ }^{\mathrm{a}, \mathrm{b}}$ \\ aDepartment of Biology, Washington University, St. Louis, Missouri, USA; ${ }^{b}$ NSF Center for Engineering Mechanobiology, Washington \\ University, St. Louis, Missouri, USA
}

\begin{abstract}
Mechanosensitive (MS) ion channels are widespread mechanisms for cellular mechanosensation that can be directly activated by increasing membrane tension. The well-studied MscS family of MS ion channels is found in bacteria, archaea, and plants. MscS-Like (MSL) 1 is localized to the inner mitochondrial membrane of Arabidopsis thaliana, where it is required for normal mitochondrial responses to oxidative stress. Like Escherichia coli MscS, MSL1 has a pore-lining helix that is kinked. However, in MSL1 this kink is comprised of two charged pore-lining residues, R326 and D327. Using single-channel patch-clamp electrophysiology in E. coli, we show that altering the size and charge of R326 and D327 leads to dramatic changes in channel kinetics. Modest changes in gating pressure were also observed while no effects on channel rectification or conductance were detected. MSL1 channel variants had differing physiological function in E. coli hypoosmotic shock assays, without clear correlation between function and particular channel characteristics. Taken together, these results demonstrate that altering pore-lining residue charge and size disrupts normal channel state stability and gating transitions, and led us to propose the "sweet spot" model. In this model, the transition to the closed state is facilitated by attraction between R326 and D327 and repulsion between R326 residues of neighboring monomers. In the open state, expansion of the channel reduces inter-monomeric repulsion, rendering open state stability influenced mainly by attractive forces. This work provides insight into how unique chargecharge interactions can be combined with an otherwise conserved structural feature to help modulate MS channel function.
\end{abstract}

\section{ARTICLE HISTORY}

Received 26 July 2020

Revised 26 August 2020

Accepted 27 August 2020

\section{KEYWORDS}

MSL1; mechanosensitive ion channel; patch-clamp electrophysiology; giant E. coli spheroplasts; Arabidopsis thaliana

\section{Introduction}

Living organisms constantly experience physical force from both internal and external sources and possess a variety of mechanisms for detecting and responding to key mechanical stimuli [1-3]. Among these mechanisms are mechanosensitive (MS) ion channels, which are found in all kingdoms of life [4-7]. Most MS channels are opened (gated) primarily by increases in lateral membrane tension [8].

While MS ion channels are united by their primary gating stimulus rather than a common mechanosensory sequence or structure, individual MS channel families have been identified by the presence of conserved domains. One such family is the MscS family, which is defined by similarity to the E. coli Mechanosensitive ion channel of $\underline{S}$ mall conductance (EcMscS) [9-11]. EcMscS, along with the Mechanosensitive ion channel of Large conductance (MscL), allows E. coli cells to survive hypoosmotic shock. Sudden transfer into a hypotonic solution leads to water entry into the cell, subsequent swelling, and presumably an increase in lateral membrane tension. Increased membrane tension in turn opens MscS and MscL, allowing for rapid osmoregulation and preventing cell damage [12-16].

Multiple structures of $E c \mathrm{MscS}$ describe a homoheptameric channel with a transmembrane (TM) domain, comprised of three TM helices per monomer, atop a large cytoplasmic "cage" [17-23]. A key feature of the $E c \mathrm{MscS}$ structure is the porelining TM helix, TM3, which, in the nonconducting state, kinks mid-way through at G113, such that its C-terminal portion points outward from the pore and lies parallel to the lipid bilayer $[17,18,20,21]$. During gating, TM3 is proposed to pivot outward around and

CONTACT Elizabeth S. Haswell ehaswell@wustl.edu Department of Biology, Mailcode 1137, Washington University in St. Louis, One Brookings Drive, Saint Louis, MO 63130 
partially straighten this kink, thus removing pore occlusions and allowing for ion flow [18,19,23,24]. Mutations to either G113 or neighboring Q112 alter channel characteristics such as desensitization/inactivation and entry into subconducting states $[25,26]$, highlighting the importance of this structural feature in shaping channel behavior.

Based on homology to the pore-lining domain and top portion of the cytoplasmic domain of $E c \mathrm{MscS}$, MscS family members have been found throughout the bacterial and archaeal kingdoms, in all currently available plant genomes, and in some protist genomes [27]. The genome of the model flowering plant Arabidopsis thaliana encodes ten homologs of EcMscS, termed MscS-Like (MSL) channels [9]. MSLs localize to various compartments, including the plasma membrane $[28,29]$, chloroplast membrane [30], and inner mitochondrial membrane [31]. Mechanosensitive channel activity has been demonstrated in heterologous systems for MSL1, MSL8, and MSL10 [31-33] and in native membranes for MSL8 and MSL10 $[28,29]$. MSL2/3 and MSL8 are involved in osmoregulation of chloroplasts and pollen, respectively $[28,32,34]$, much like EcMscS in E. coli cells. However, MSL10 has a cell-death signaling activity that is separable from its MS channel activity [35,36], revealing MSL function beyond maintaining osmotic homeostasis.

MSL1 is localized to the inner membrane of mitochondria and appears to be involved in regulating the redox status of mitochondria during stress [31]. Of all the Arabidopsis MSLs, it most closely resembles $E c \mathrm{MscS}$ in overall structure, channel behavior, and sequence. Structural and biochemical analyses of MSL1 revealed a homoheptameric channel consisting of a TM domain, comprised of 5 TM helices per monomer, atop a large cage region likely located in the mitochondrial matrix [31,37,38]. MSL1 and $E c \mathrm{MscS}$ are both slightly anion-preferring and have average conductances of $\sim 1.2 \mathrm{nS}$ at negative membrane potentials $[26,31,39]$. However, compared to $E c M s c S$, MSL1 shows stronger rectification (a directional preference for ion flow) and stronger hysteresis (a difference in open and closing tensions), with a preference for transporting anions out of the cell, and with channel closure often occurring at lower membrane tension than channel opening [40-42]. A sequence alignment (Figure 1(a)) revealed strong conservation between the pore-lining helices of MSL1 and $E c M s c S$ with a singular exception: two neighboring residues are charged in MSL1 (R326 and D327) and polar in EcMscS (Q112 and G113) (red box, Figure 1(a)).

Rectification of MSL1 is also strong compared to other MscS family members for which this feature has been characterized [31] and most closely resembles that of MscS-like activity detected in V. cholerae cells [43]. One of the three MscS-like genes from $V$. cholerae also encodes a positively charged and a negatively charged residue at the same positions as R326 and D327 (Figure 1(a)). With the exception of MSC1 from Chlamydomonas reinhardtii chloroplasts and MscMJ from Methanocaldococcus jannaschi [5,44], other MscS family members from archaea, bacteria, and plants show only mild rectification [26,28,33,45-47]. While the correlation between charged residues and rectification in the $\mathrm{MscS}$ family is not strict, charged residues have been demonstrated to control rectification in other channels [48].

Recently reported cryoEM structures of MSL1 in the closed state $[37,38]$ place R326 and D327 at the kink of the pore-lining helix TM5, which is bent such that its C-terminal half runs parallel to the bilayer (Figure 1(b)), similar to TM3 in the non-conducting state of $E c M s c S$. In the MSL1 ${ }^{\mathrm{A} 320 \mathrm{~V}}$ structure, proposed to represent the open state [37], TM5 is almost completely straight and sits diagonally within the bilayer (Figure 1(c)). These structures support a gating transition in which neighboring R326 and D327 side chains point inward from the TM5 kink in the closed state (Figure 1(d)), then are pushed toward each other and away from the pore during opening (Figure 1(e)). TM5 helices from neighboring monomers also move farther apart during channel opening. As with Q112 and G113 of EcMscS $[25,26]$, altering R326 and D327 of MSL1 may affect kink formation and thus channel behavior.

In this study, we investigated the roles of R326 and D327 in MSL1 rectification and other hallmarks of MSL1 channel behavior using single-channel patch-clamp electrophysiology and physiological assays in E. coli. Our results provide insight into the roles of individual residues in the MSL1 porelining helix and validate recently published MSL1 cryoEM structures [37,38]. More broadly, our study contributes to an understanding of how the specific 
MSL1 229-VQS I L T VGGVGGVATAFAARDI L GNVLSGL - SMQFSRP EcMscS 93- TAS I A V L GAGLAVGLALQGSLSNLAAGV-LLVMFRP VcMscS 99- TASVVAVIGAAGLAVGLALQGSLSNFAAGV-LIVAFRP VcMscS_2 369- L A P V L T GFG I A GV I I GFA LQD T L NFAAGM - MLL I YRP VcMscS_3 165-PVI L L S G L G AMTAVFMLVFKDP I L G L VAGV-QLSANKM MSC1 304- LKPLLAVGGASG I I I GLATQQVLGNFVSGL - N I FLSRP MscMJLR $165-$ I K T L L A G L I G G A A A L A SQNLVSNL I A G - I I L T D K P MscMJ 158- I T A L A A L V VGLALALAMQDT I KNF I AG I - L I L I DK MscSP 81- ATS I VAVLGAASLA I GLALQGTLSDLAAGV-MLVVFRP MscCG 93- LAGAA I PATIASAA I GLGAQS I VADFLAGF- F I L TEKQ MSL10 537- T T KVLLFFS TQLVALAF I I G S T C KNLFES I VFVFVMHP MSL8 694- S SKVLLFVS SQVVLLAF I FGNTVKTVFES I I F L F I VHP

b

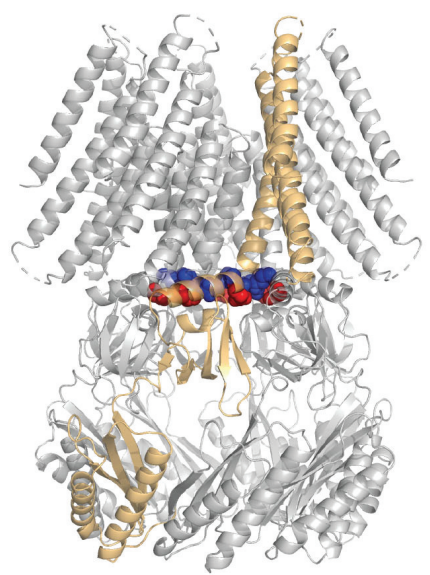

C

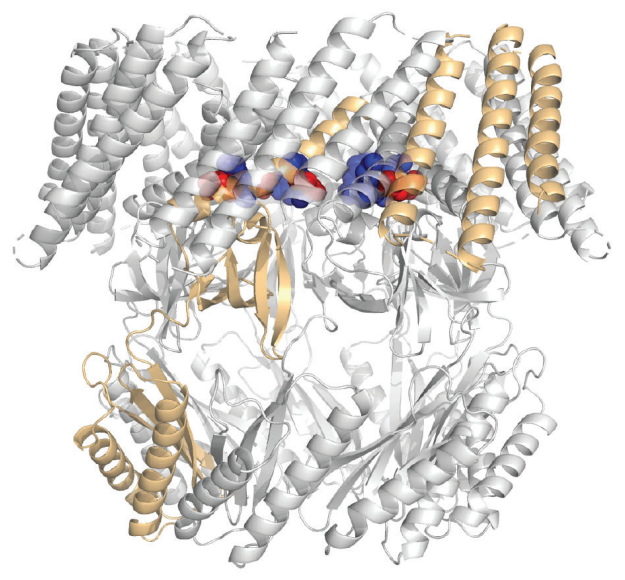

d

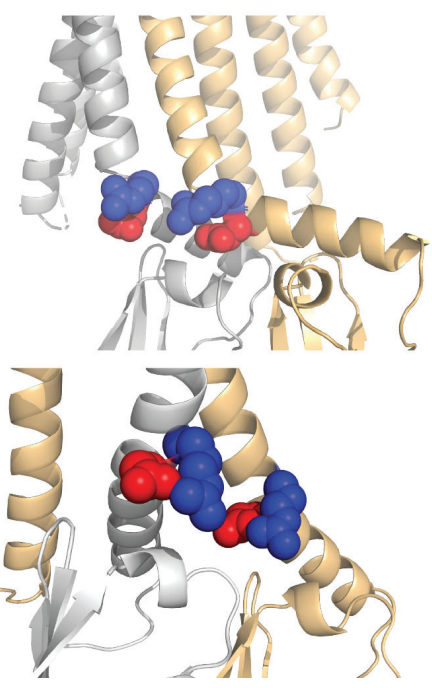

Figure 1. R326 and D327 are charged residues in the kinked pore-lining TM5 helix of the MS ion channel MSL1. (a) Alignment of pore-lining helices from MscS family members for which rectification information is available. Nonpolar residues are gray, polar residues white, positively charged residues blue, negatively charged residues red, and other residues yellow. R326 and D327 of MSL1 and the corresponding residues in other MscS family members are highlighted by a red box. (b-e) Images of cryoEM structures of MSL1 (PDB file 6VXM [37]) and MSL1 ${ }^{\text {A320V }}$ (PDB file 6VXN [37]) in closed and open states, respectively. One monomer is light orange and residues R326 (blue) and D327 (red) are indicated. (b, c) Side view of the placement of R326 and D327 in the TM5 kink of MSL1 (b) and MSL1 ${ }^{\text {A320V }}$ (c) multimers, respectively. (d, e) Close-up view of the R326 and D327 residues in two adjacent monomers, one gray and one light orange, as viewed from inside the MSL1 (d) and MSL1 ${ }^{\mathrm{A} 320 \mathrm{~V}}$ (e) pores.

composition of common structural features, like the kinked pore-lining helix found in the MscS family, can influence properties of MS ion channels.

\section{Materials and methods}

\section{Subcloning and $E$. coli strains}

The MSL1 sequence lacking the putative $\mathrm{N}$-terminal mitochondrial transit peptide sequence (residues 1-79 [31];), codon-optimized for translation in E. coli, was synthesized (ThermoFisher Scientific, USA), and cloned into the pET300 vector to create pET300MSL1. A C-terminal GFP tag was then added before the stop codon of MSL1 with an EcoRI cut site as the linker sequence between MSL1 and GFP to create pET300-MSL1-GFP. Site-directed mutagenesis was then used to create pET300-MSL1 ${ }^{\mathrm{R} 326 \mathrm{Q}_{-}}$GFP, pET300-MSL1 $^{\text {D327G }}$-GFP, pET300-MSL1 ${ }^{\text {R326Q D327G }}$

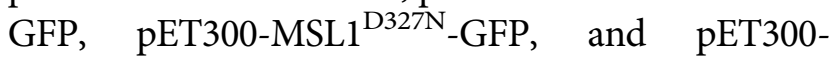
MSL1 $^{\text {R326Q D } 327 N}$-GFP (primer sequences in Table $\mathrm{S} 1)$. Mutations were verified using restriction enzyme 
digest and sequencing; the R326Q mutation causes the loss of a PmlI site, the D327G mutation creates an EcoRI site, and the D327N mutation creates a SspI site. To create pET300-MscS-GFP, the MSL1 sequence was replaced with the full-length $E c M s c S$ sequence. Lysogenization of E. coli strains FRAG-1 [49], MJF465 [15], MJF641, and MJF516 [50] was performed using the Novagen $\lambda \mathrm{DE} 3$ Lysogenization Kit (Millipore Sigma) following manufacturer's instructions. Lysogenized strains used in this study are indicated by (DE3).

\section{Sequence alignment and functional predictions}

The MSL1 cryoEM structures (RCSB Protein Data Bank, PDB ID 6VXM [37] and 6LYP [38]) were visualized and images generated using PyMol (Schrödinger, Inc.). MscS family member protein sequences were obtained from publicly available databases with accession numbers as follows: Escherichia coli MscS (EcMscS), UniProt ID P0C0S2; Arabidopsis thaliana MSL1 (MSL1), At4g00290; Arabidopsis thaliana MSL8 (MSL8), At2g17010; Arabidopsis thaliana MSL10 (MSL10), At5g12080; Corynebacterium glutamicum MscCG, RefSeq WP_011014245.1; Chlamydomonas reinhardtii MSC1, GenBank ID AB288852.1; Silicibacter pomeroyi MscSP, UniProt ID Q5LMR6; Methanococcus maripaludis MscMJ, UniProt ID Q6M0K6; M. jannaschii MscMJLR, UniProt ID Q58543. Structural features of sequences were either assigned based on previously published structural data or, when none was available, predicted using the TMHMM server, v 2.0 (DTU HealthTech). Sequences of 70 amino acids containing predicted or known pore-lining sequences were then aligned in Unipro UGENE software using the built-in MUSCLE algorithm.

\section{MSL1 variant expression and localization in E. coli}

Approximately 10 colonies of MJF465(DE3) cells expressing GFP-tagged MSL1 variants were placed into a $14 \mathrm{~mL}$ culture tube with $3 \mathrm{~mL} \mathrm{LB}+1 \mathrm{mM}$ carbenicillin and shaken at $37^{\circ} \mathrm{C}, 250 \mathrm{rpm}$ to an $\mathrm{OD}_{600}$ of $\sim 0.5$. TwomL of this culture was added to $100 \mathrm{~mL} \mathrm{LB}+1 \mathrm{mM}$ carbenicillin and shaken at $37^{\circ} \mathrm{C}, 250 \mathrm{rpm}$ until $\mathrm{OD}_{600} \sim 0.5$. Isopropyl $\beta$ -
D-1-thiogalactopyranoside (IPTG) was then added to a final concentration of $1 \mathrm{mM}$ and cultures shaken at $37^{\circ} \mathrm{C}, 250 \mathrm{rpm}$ for either $30 \mathrm{~min}$ (for expression of MscS-GFP and GFP) or 1 hour (for expression of untagged MSL1 and GFP-tagged MSL1 variants). To image GFP signal, cells were placed on a $1 \%$ agarose pad, covered with a coverslip, then imaged using an Olympus FV3000 confocal microscope. GFP was excited using a $488 \mathrm{~nm}$ laser and GFP emission was collected from 493 to $533 \mathrm{~nm}$. For images of cells expressing cytoplasmic GFP, laser transmissivity was 5\% and PMT voltage was $436 \mathrm{~V}$. For cells expressing either a GFP-tagged MSL1 variant or MscS-GFP, laser transmissivity was set at $6 \%$ and PMT voltage was $515 \mathrm{~V}$. Both bright field and GFP fluorescence images were taken for each sample.

\section{Patch-clamp electrophysiology}

Giant E. coli spheroplasts were made according to [51]. The MJF641(DE3) strain was used for conductance analysis, MJF516(DE3) cells for tension sensitivity measurements, and either MJF641 (DE3) or MJF516(DE3) cells for channel activity duration, open state dwell time, and closed state dwell time measurements. Cells were transformed with the appropriate expression constructs and grown overnight on LB plates containing $1 \mathrm{mM}$ carbenicillin at $37^{\circ} \mathrm{C}$. Cells were then cultured in LB with $1 \mathrm{mM}$ carbenicillin at $37^{\circ} \mathrm{C}, 250 \mathrm{rpm}$ to an $\mathrm{OD}_{600}$ of $0.4-0.5$, then diluted $1: 10$ in $30 \mathrm{~mL} \mathrm{LB}+$ $60 \mu \mathrm{g} / \mathrm{mL}$ cephalexin (without carbenicillin) and shaken at $42^{\circ} \mathrm{C}, 180 \mathrm{rpm}$ until cells reached $75-100 \mu \mathrm{m}$ in length. IPTG was added to each culture to a final concentration of $1 \mathrm{mM}$ and cultures shaken at $42^{\circ} \mathrm{C}, 180 \mathrm{rpm}$ for 1 hour. Cultures were incubated at $4^{\circ} \mathrm{C}$ overnight, then spun down at $3000 \mathrm{xg}$. Cell pellets were gently resuspended in $2.5 \mathrm{~mL} 0.8 \mathrm{M}$ sucrose and the following spheroplast reaction components added in order to the resuspension, with gentle swirling after each addition: $150 \mu \mathrm{L} 1 \mathrm{M}$ Tris- $\mathrm{HCl}(\mathrm{pH} 7.2)$, $120 \mu \mathrm{L} 5 \mathrm{mg} / \mathrm{mL}$ lysozyme, $50 \mu \mathrm{L} 5 \mathrm{mg} / \mathrm{mL}$ DNase I, $150 \mu \mathrm{L} 0.125 \mathrm{M}$ EDTA. The reaction was incubated at room temperature for 5-7 $\mathrm{min}$, then stopped by adding $1 \mathrm{~mL}$ stop solution (0.68 M sucrose, $19 \mathrm{mM} \mathrm{MgCl}_{2}, 9.5 \mathrm{mM}$ Tris- $\mathrm{HCl} \mathrm{pH}$ $7.2,0.22 \mu \mathrm{m}$ filter-sterilized) and swirling to mix. 
$3.5 \mathrm{~mL}$ dilution solution $(0.78 \mathrm{M}$ sucrose, $1 \mathrm{mM}$ $\mathrm{MgCl}_{2}, 1 \mathrm{mM}$ Tris- $\mathrm{HCl} \mathrm{pH} 7.2,0.22 \mu \mathrm{m}$ filtersterilized) was added, and $275 \mu \mathrm{L}$ aliquots stored at $-80^{\circ} \mathrm{C}$

All data were collected from inside-out configuration patches. The pipette buffer used was $200 \mathrm{mM} \mathrm{KCl}, 90 \mathrm{mM} \mathrm{MgCl}_{2}, 5 \mathrm{mM} \mathrm{CaCl}_{2}$, $5 \mathrm{mM}$ HEPES, $\mathrm{pH}$ 7.4. The bath buffer was identical to the pipette buffer, with the addition of $400 \mathrm{mM}$ sucrose. Pressure application was controlled using an HSPC-1 pressure clamp system (ALA Scientific Instruments) and data were acquired using an Axopatch 200B amplifier and a Digidata 1440A digitizer (Molecular Devices) at $20 \mathrm{kHz}$ and low-pass filtered at $5 \mathrm{kHz}$ except for channel activity duration, open state dwell time, and closed state dwell time measurements, for which data were collected at $10 \mathrm{kHz}$. Data were analyzed using Clampfit 10.6 (Molecular Devices).

Conductance measurements were performed at membrane potentials ranging from $-150 \mathrm{mV}$ to $80 \mathrm{mV}$ using $5 \mathrm{~s}$ symmetric pressure ramps. The largest conductance value for each gating event was taken to avoid including potential substate conductance measurements in the average conductance calculations. Conductances were then calculated using Ohm's law at membrane potentials of $-120 \mathrm{mV},-60 \mathrm{mV}$, and $60 \mathrm{mV}$.

Tension sensitivity of MSL1 variants was assessed by determining the gating pressure of MSL1 or an MSL1 variant relative to that of endogenously expressed MscL, using 5-10 s symmetric pressure ramps at a membrane potential of $-70 \mathrm{mV}$. The first gating events observed for each channel in a single trace were used and only MSL1 gating events lasting a minimum of $1 \mathrm{~s}$ were considered. Data were only analyzed if both MSL1 variant and MscL gating events were observed in the same trace and if no MSL1 variant gating events were observed prior to application of additional negative pressure to the patch.

Open state dwell time, closed state dwell time, and channel activity duration measurements were performed using a 2-4 s symmetric pressure ramp followed by monitoring of channel activity until $97.7 \mathrm{~s}$ after the start of the pressure ramp. Membrane potential was maintained at $-70 \mathrm{mV}$ throughout the course of this protocol. Traces were not analyzed if channel activity was detected prior to application of the pressure ramp, and open and closed state dwell times were only measured for traces in which a single gating event occurred. Open state dwell time was determined by measuring the duration of the first pressure-triggered gating event for each patch, regardless of the length of its subsequent closure. Closed state dwell time was defined as the amount of time between the initial pressuretriggered gating event and a second gating event within the same trace. Instances in which either no additional gating event occurred or when the initial pressure-triggered gating event lasted until the end of the trace were noted as separate categories. The channel activity duration was defined as the length of time between the start of the first pressure-triggered gating event and the first channel closure lasting for $\geq 5 \mathrm{~s}$. Results from individual traces were pooled from 7 to 10 patches per channel to determine open and closed state dwell times and from 9 to 10 patches per channel to determine channel activity durations measurements. For each measurement, events were sorted into one of five bins: 0-19.99 s, 20-39.99 s, 40-59.99 s, 60-79.99 s, $80+s$, with the additional categories of "No Closure" and "No Re-Opening" for closed state dwell time measurements.

\section{E. coli growth assay}

Five freshly transformed MJF465(DE3) colonies were grown at $37^{\circ} \mathrm{C}, 250 \mathrm{rpm}$ in $\mathrm{LB}$ with $1 \mathrm{mM}$ carbenicillin to an $\mathrm{OD}_{600}$ of $\sim 0.5$. Cultures were then diluted to an $\mathrm{OD}_{600}$ of 0.05 in either $\mathrm{LB}$ only or LB $+1 \mathrm{mM}$ IPTG and three $250 \mu \mathrm{L}$ aliquots of each dilution transferred to a clear, flat-bottom 96well plate. This plate was then placed in an Infinite M200 Pro plate reader, then incubated at $37^{\circ} \mathrm{C}$ with continuous shaking and $\mathrm{OD}_{600}$ measurements made every $15 \mathrm{~min}$ for a total of $6 \mathrm{~h}$. Growth assays were repeated using cells from three independent transformations.

\section{E. coli hypoosmotic shock survival assay}

Assays were conducted as described in [52] with some modifications. Freshly transformed colonies were grown overnight at $37^{\circ} \mathrm{C}, 250 \mathrm{rpm}$ in low glucose 
citrate-phosphate media $\left(60 \mathrm{mM} \mathrm{Na}_{2} \mathrm{HPO}_{4}, 5 \mathrm{mM} \mathrm{K}_{2}\right.$ $\mathrm{HPO}_{4}, 7 \mathrm{mM}$ citric acid, $7 \mathrm{mM} \mathrm{NH} \mathrm{SO}_{4}, 0.4 \mathrm{mM}$ $\mathrm{MgSO}_{4}, 3 \mu \mathrm{M}$ thiamine, $6 \mu \mathrm{M}$ iron) with $0.04 \%$ glucose and $1 \mathrm{mM}$ carbenicillin. Overnight cultures were diluted $1: 5$ in citrate-phosphate media with $0.2 \%$ glucose and grown to an $\mathrm{OD}_{600}$ of $\sim 0.3$ at $37^{\circ} \mathrm{C}, 250 \mathrm{rpm}$. Cultures were then diluted 1:1 in citrate-phosphate media with $0.2 \%$ glucose and $1 \mathrm{M} \mathrm{NaCl}$ and grown to an $\mathrm{OD}_{600}$ of $\sim 0.3$, at which point expression was induced for 1 hour by the addition of $1 \mathrm{mM}$ IPTG. Cultures were diluted 1:20 in either $\mathrm{ddH}_{2} \mathrm{O}$ for shocked samples or $0.5 \mathrm{M} \mathrm{NaCl}$ citrate-phosphate buffer $\left(60 \mathrm{mM} \mathrm{Na} 2 \mathrm{HPO}_{4}, 5 \mathrm{mM} \mathrm{K} \mathrm{HPO}_{4}, 7 \mathrm{mM}\right.$ citric acid, $7 \mathrm{mM} \mathrm{NH}_{4} \mathrm{SO}_{4}$ ) for unshocked controls and shaken at $37^{\circ} \mathrm{C}, 250 \mathrm{rpm}$ for $15 \mathrm{~min}$. Cultures were serially diluted 1:10 six times in either $\mathrm{ddH}_{2}$ $\mathrm{O}$ (shocked samples) or $0.5 \mathrm{M} \mathrm{NaCl}$ citratephosphate buffer (unshocked controls). A $5 \mu \mathrm{L}$ aliquot of each dilution was then spotted onto $\mathrm{LB}+$ carbenicillin plates and grown overnight at $30^{\circ} \mathrm{C}$. The next day, the number of colonies grown from each dilution were counted and survival ratios of shocked/ unshocked colonies calculated for each strain/construct combination using values from dilutions producing up to 50 colonies.

\section{Results}

To begin to study the role of R326 and D327 in MSL1 function, an E. coli codon-optimized version of MSL1 lacking the predicted mitochondrial target sequence (2-79 aa [31];) was fused to GFP and expressed from the T7-inducible pET300 vector. For all experiments, constructs were transformed into lysogenized E. coli containing IPTG-inducible T7 promoters (see Methods). Four different lysogenized E. coli strains were used: MJF465(DE3) $\left(m s c S^{-} m s c K^{-} m s c L^{-}[15]\right)$, MJF516(DE3) $\left(m s c S^{-}\right.$ $m s c K^{-} y b i O^{-} y j e P^{-}$[50]), MJF641(DE3) $\left(m s c S^{-}\right.$ $m s c K^{-} y b d G-y b i O^{-} y j e P^{-} y n a I^{-} m_{s c L}^{-}$[50]), and their parental strain FRAG-1(DE3) [49].

\section{GFP-tagged MSL1 variants localize to the periphery of $E$. coli cells and do not strongly affect cell growth}

We assessed the expression and localization of GFP-tagged MSL1 variants in E. coli strain MJF465(DE3) cells by imaging induced cells using a confocal microscope (Figure 2(a)). All versions of GFP-tagged MSL1 produced punctate GFP signal around the cell periphery that was similar to EcMscS-GFP (as previously observed $[53,54])$, and distinct from cytoplasmic-free GFP. Growth rates of all strains showed only minor differences (Figure 2(b-c)) [55].

\section{Mutations to R326 and D327 do not alter channel conductance or rectification}

We next sought to characterize the channel behavior of MSL1-GFP variants using single-channel patch-clamp electrophysiology in giant E. coli spheroplasts as in [51]. IV curves with membrane potentials ranging from $-150 \mathrm{mV}$ to $80 \mathrm{mV}$ for each GFP-tagged MSL1 variant are shown in Figure 3. As demonstrated previously [31], MSL1GFP channel activity was triggered by application of suction to inside-out excised patches and was characterized by a single-channel conductance of $\sim 1.2 \mathrm{nS}$ at negative membrane potentials and markedly reduced conductance at membrane potentials greater than $20 \mathrm{mV}$. No major differences were observed between the IV curves of MSL1-GFP and any GFP-tagged MSL1 variant. Thus, none of the mutations to R326 nor D327 we tested changed the rectification behavior of MSL1.

The IV curves shown in Figure 3 were used to calculate conductance at $60 \mathrm{mV},-60 \mathrm{mV}$, and $-120 \mathrm{mV}$ for each GFP-tagged MSL1 variant (Table 1). The single-channel conductances of $\mathrm{MSL1}^{\mathrm{R} 326 \mathrm{Q}} \mathrm{D} 327 \mathrm{G}_{-}$GFP and MSL1 ${ }^{\mathrm{R} 326 \mathrm{Q}} \mathrm{D} 327 \mathrm{~N}_{-}$ GFP were significantly lower than that of MSL1GFP at $-60 \mathrm{mV}(0.82 \pm 0.08 \mathrm{nS}, 0.81 \pm 0.11 \mathrm{nS}$, and $1.19 \pm 0.10 \mathrm{nS}$, respectively). However, no significant differences in conductance between any variants were detected at $60 \mathrm{mV}$ nor $-120 \mathrm{mV}$. Conductances at $-120 \mathrm{mV}$ are the most physiologically relevant, as plant mitochondria maintain very negative inner membrane potentials [56,57]. We also note that in [38], MSL1 $^{\text {R326Q D327G }}$ showed reduced single-channel current but greater total current than MSL1. While this was interpreted to a higher number of channels open, this could also be due to longer open state dwell times, as described below. Taken together, the data shown in Figures 2,3, and Table 
a
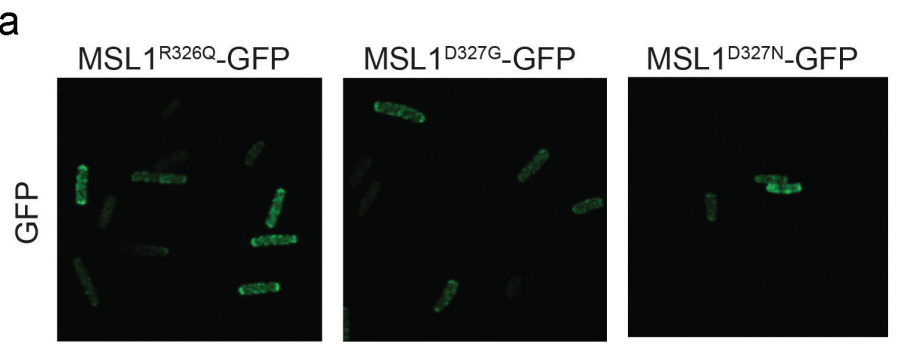

MSL1R326Q D327G

MSL1 ${ }^{\text {R326Q D327N }}$
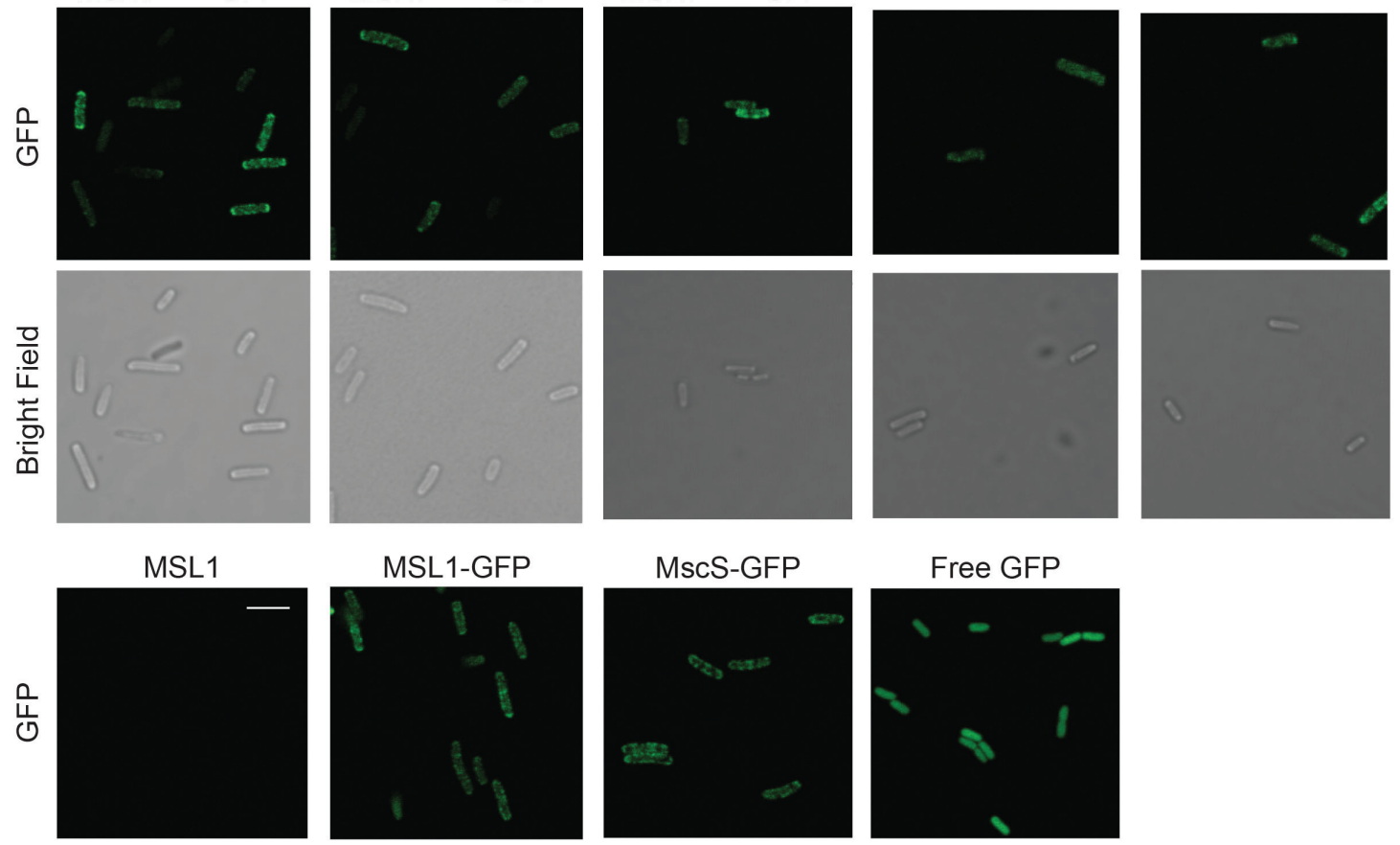

MSL1-GFP

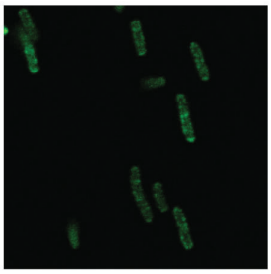

MscS-GFP
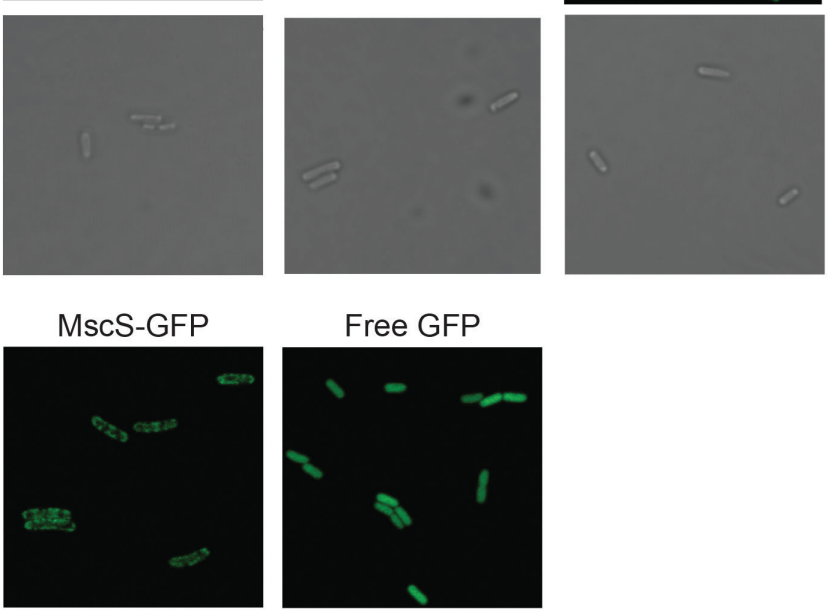

Free GFP
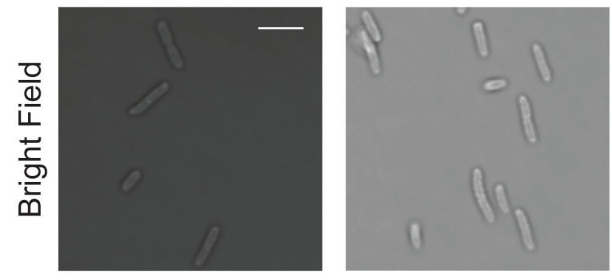

b
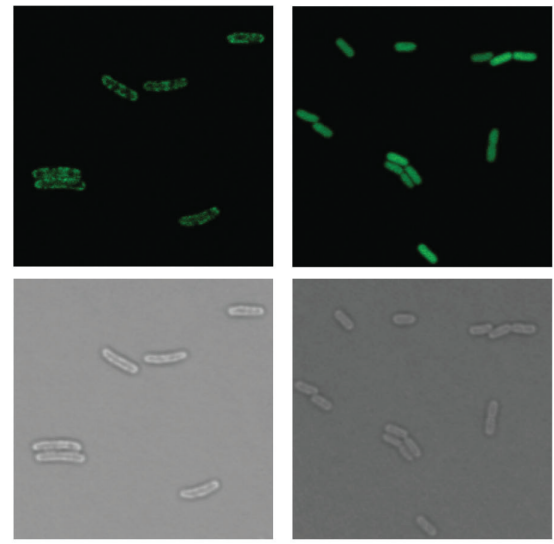

C
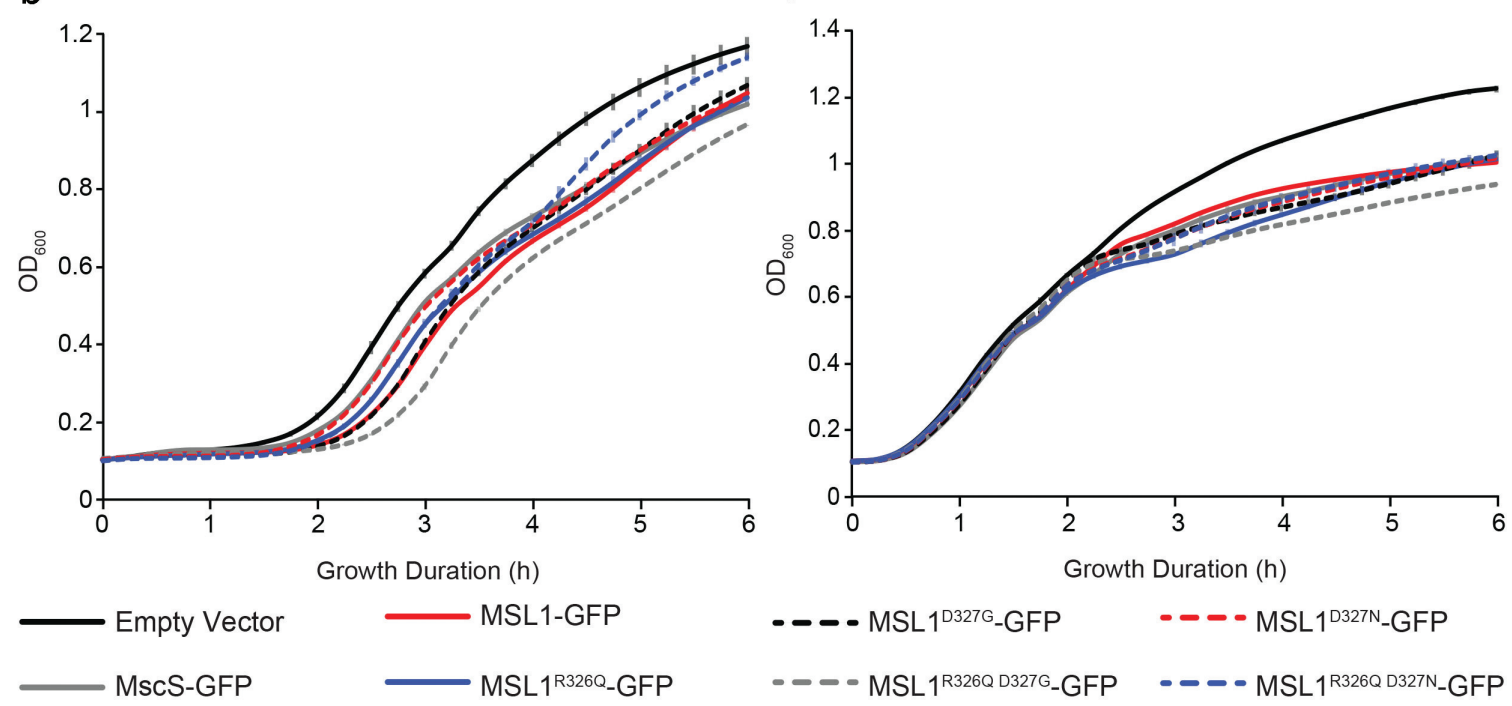

Figure 2. MSL1 variants localize to $E$. coli cell membranes and do not strongly impact $E$. coli cell growth in LB. (a) Confocal micrographs of MJF465(DE3) cells expressing untagged MSL1, MSL1-GFP, GFP-tagged MSL1 variants, ECMsCS-GFP, or cytoplasmic GFP. Scale bars are $5 \mu \mathrm{m}$. (b-c) Growth curves of MJF465(DE3) cells transformed with pET300 vectors encoding the indicated protein or an empty pET21b(+) control. Cells were grown in LB with (b) or without (c) IPTG and $\mathrm{OD}_{600}$ values measured every 15 min. Data points are shown \pm standard deviation, although error bars may be too small to be visible. 
a

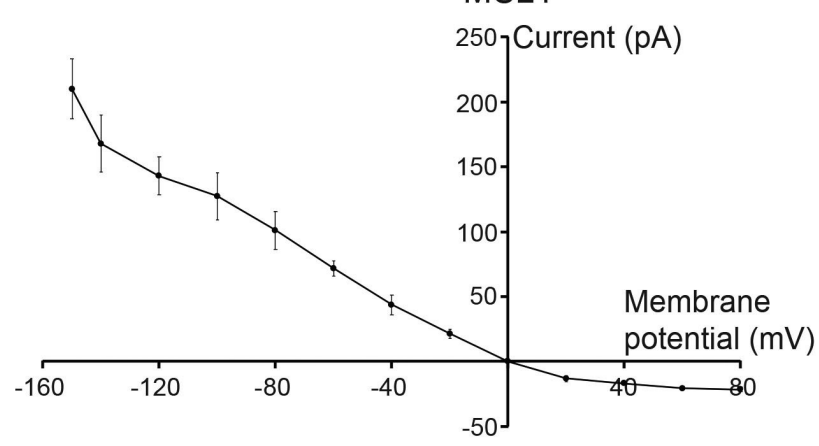

C

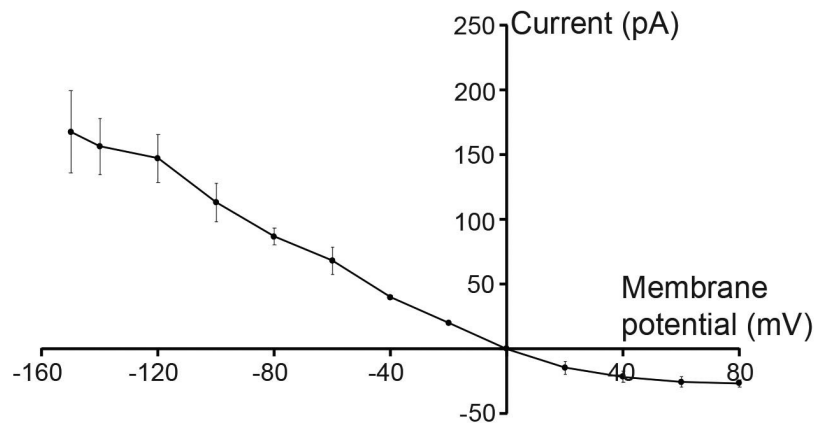

e

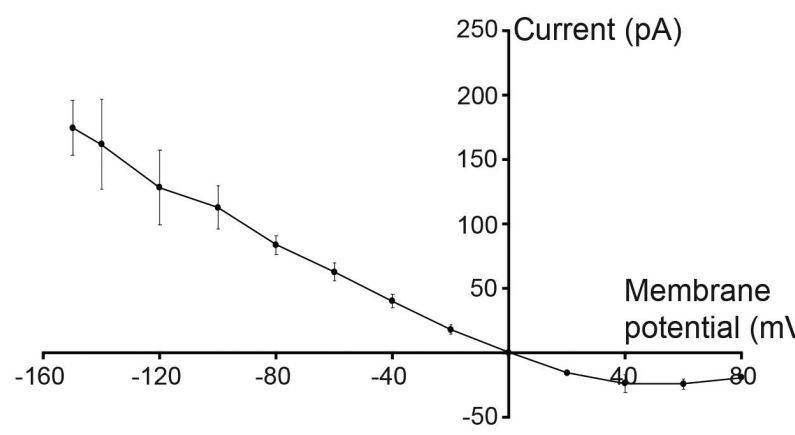

b

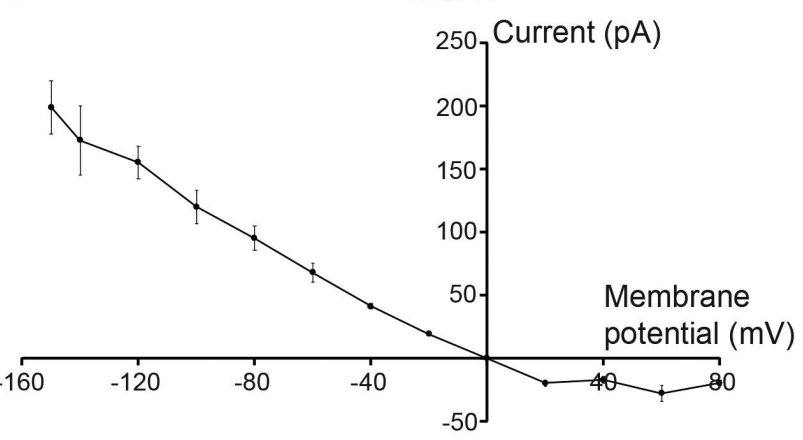

d

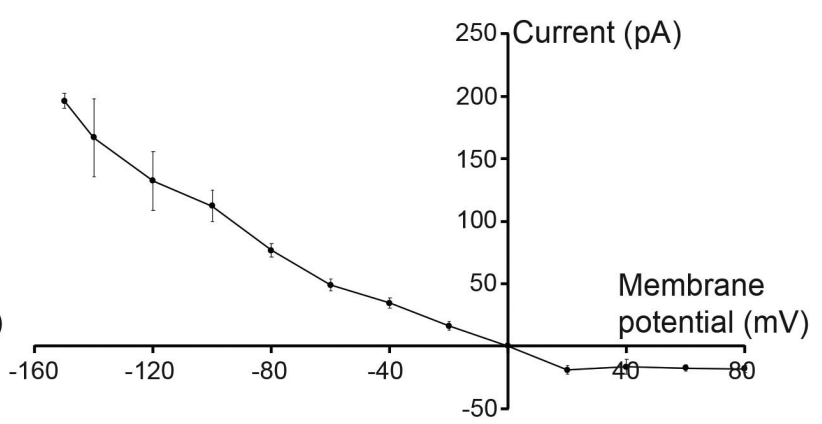

$\mathrm{f}$

MSL1 $1^{\text {R326Q D327N }}$

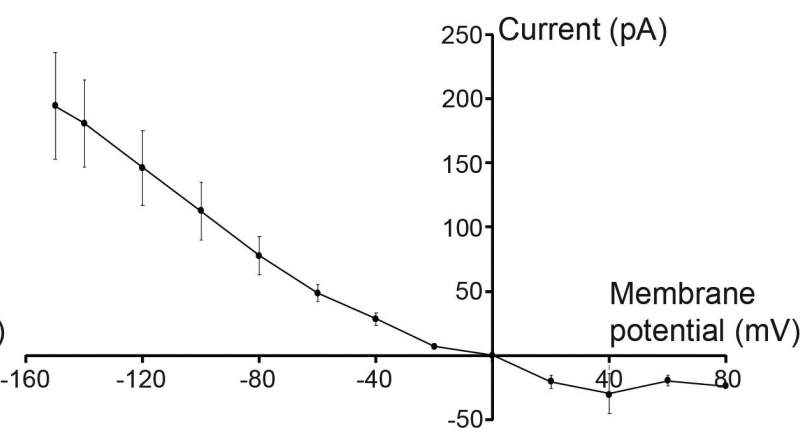

Figure 3. Mutations to R326 and D327 of MSL1 do not affect rectification. IV curves for GFP-tagged MSL1 variants expressed in MJF641(DE3) cells. Each data point represents the average single-channel current for 3 to 17 patches. Error bars indicate standard deviation.

Table 1. Mutations to R326 and D327 in MSL1 have little effect on channel conductance. Conductance values represent the mean of average patch conductances for 3-7 patches per variant. Differences were statistically evaluated using one-way ANOVA with post-hoc Scheffe's test; letters indicate statistical differences $(p<0.05)$.

\begin{tabular}{|c|c|c|c|}
\hline \multirow[t]{2}{*}{ MSL1 Variant } & \multicolumn{3}{|c|}{ Conductance (nS) } \\
\hline & $-120 \mathrm{mV}$ & $-60 \mathrm{mV}$ & $60 \mathrm{mV}$ \\
\hline MSL1 & $1.19 \pm 0.12^{\mathrm{a}}$ & $1.19 \pm 0.10^{\mathrm{a}}$ & $0.34 \pm 0.02^{\mathrm{a}}$ \\
\hline MSL1 ${ }^{\text {R326Q }}$ & $1.29 \pm 0.11^{\mathrm{a}}$ & $1.13 \pm 0.12^{\mathrm{a}}$ & $0.46 \pm 0.11^{\mathrm{a}}$ \\
\hline MSL1 ${ }^{\text {D327G }}$ & $1.22 \pm 0.15^{\mathrm{a}}$ & $1.14 \pm 0.17^{\mathrm{a}}$ & $0.42 \pm 0.06^{a}$ \\
\hline MSL1 ${ }^{\text {R326Q D327G }}$ & $1.10 \pm 0.20^{\mathrm{a}}$ & $0.82 \pm 0.08^{b c}$ & $0.29 \pm 0.04^{\mathrm{a}}$ \\
\hline MSL1 ${ }^{\text {D327N }}$ & $1.07 \pm 0.24^{\mathrm{a}}$ & $1.04 \pm 0.12^{\mathrm{ab}}$ & $0.41 \pm 0.07^{\mathrm{a}}$ \\
\hline MSL1 ${ }^{\text {R326Q D327N }}$ & $1.22 \pm 0.24^{\mathrm{a}}$ & $0.81 \pm 0.11^{c}$ & $0.33 \pm 0.07^{\mathrm{a}}$ \\
\hline
\end{tabular}


1 indicate that the size and charge at 326 and 327 are not critical for protein stability, localization, or single-channel conductance. Unexpectedly, changing R326 and D327 to the analogous resides in $E c M s c S$ did not reduce MSL1 rectification (Figure 3).

\section{Mutations to R326 and D327 have modest effects on MSL1 tension sensitivity}

Given that R326 and D327 did not affect rectification, we next examined their role in the gating process of MSL1. We started by determining the gating pressure of each MSL1-GFP variant. Gating pressure is a proxy for tension sensitivity; for MS channels in E. coli it is often measured relative to endogenously expressed MscL and reported as the pressure threshold ratio $\left(\mathrm{P}_{\mathrm{x}} / \mathrm{P}_{\mathrm{L}}\right)$ [58]. We expressed each GFP-tagged MSL1 variant in E. coli strain MJF516(DE3) [50] and generated giant spheroplasts. Using 5-10 s pressure ramps, we measured gating pressures of the first channel openings of each GFP-tagged MSL1 variant and of MscL, and calculated the $\mathrm{P}_{\mathrm{x}} / \mathrm{P}_{\mathrm{L}}$ values for each variant (Figure 4). MSL1 ${ }^{\mathrm{R} 326 \mathrm{Q}} \mathrm{D} 327 \mathrm{G}_{-} \mathrm{GFP}$, MSL1 ${ }^{\text {D327N }}-$ GFP, and MSL1 ${ }^{\text {R326Q D327N }}$-GFP had significantly higher $\mathrm{P}_{\mathrm{x}} / \mathrm{P}_{\mathrm{L}}$ than MSL1-GFP (0.65-0.71 compared to 0.49 , respectively). In contrast, pressure threshold ratios of $\mathrm{MSL1}^{\mathrm{R} 326 \mathrm{Q}}-\mathrm{GFP}$,

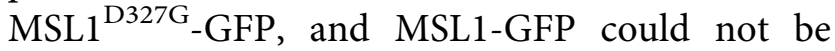
statistically distinguished, although the average $\mathrm{P}_{\mathrm{x}}$ $/ \mathrm{P}_{\mathrm{L}}$ of individual patches containing $\mathrm{MSL1}^{\mathrm{D} 327 \mathrm{G}}{ }_{-}$ GFP were typically lower than those of MSL1GFP. These results thus indicate that both size and charge at the MSL1 TM5 kink influence gating pressure, and the residue at 327 appears to play a dominant role.

\section{R326 and D327 exert dramatic and opposing effects on channel kinetics}

We also examined the channel activity duration, a parameter we previously referred to as open state dwell time [37], open state dwell time, and closed state dwell time of GFP-tagged MSL1 variants (Figure 5). These measurements allowed us to analyze the gating kinetics of our MSL1 variants without achieving patch saturation, as low expression of our GFP-tagged MSL1 variants produce low numbers of channels per patch, as seen previously [37]. As in [37], we used a modified version of a previously published protocol [25].

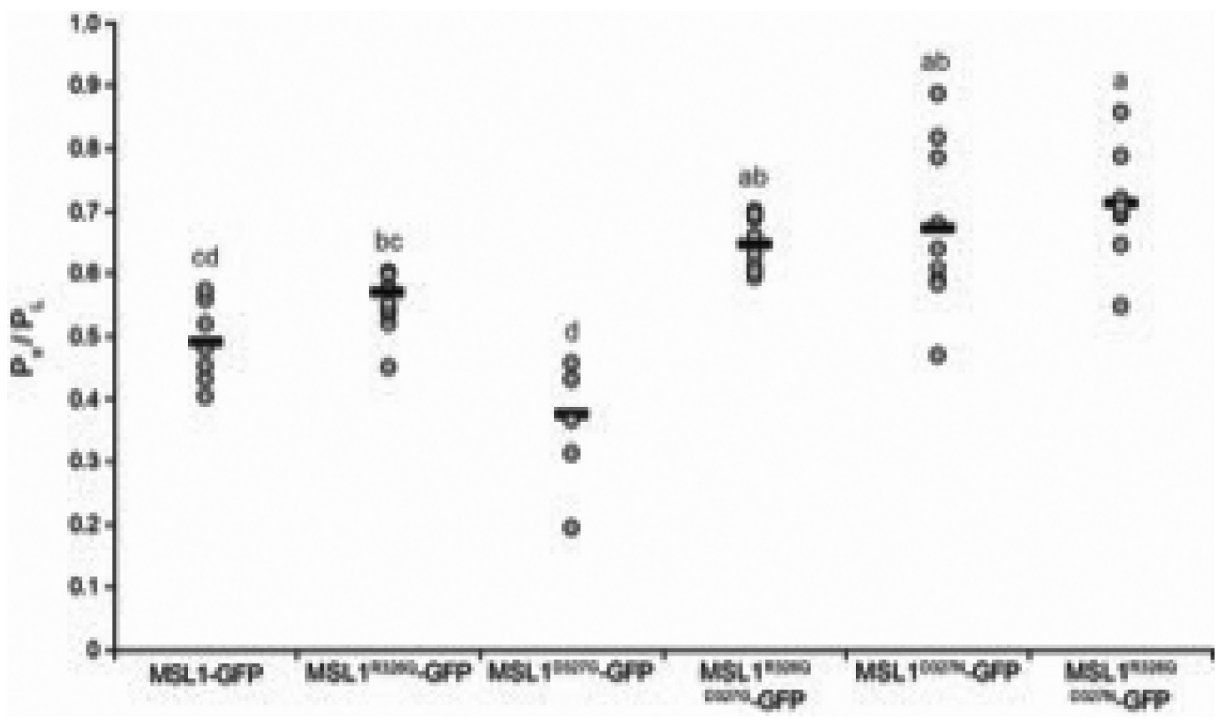

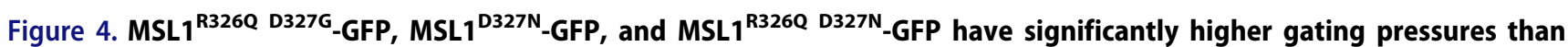
MSL1-GFP. Gating pressures of the indicated GFP-tagged MSL1 variants relative to the gating pressures of endogenously expressed MscL. Channels were gated using 5-10 s symmetric pressure ramps at a membrane potential of $-70 \mathrm{mV}$. Each gray circle represents the average of all gating pressure ratios obtained for a single patch, while the black bars represent the mean of patch averages for each sample. $\mathrm{N}=6-10$ patches per variant. Statistical differences are indicated by different letters and were determined using oneway ANOVA followed by Scheffe's post-hoc test; $p<0.05$ ). Data points greater than two standard deviations beyond the sample average were excluded. 
Mechanosensitive gating was triggered by applying a brief 2-4 $\mathrm{s}$ negative pressure ramp at a membrane potential of $-70 \mathrm{mV}$, then this membrane potential was maintained without any additional suction for a total of $100 \mathrm{~s}$.

Channel activity duration was defined as the time from the initial pressure-triggered channel opening to final channel closure, as indicated by the complete cessation of channel activity for 5 s. Using this protocol, most (89\%) MSL1-GFP activity lasted less than $20 \mathrm{~s}$ and only $3.3 \%$ of activities lasted more than $80 \mathrm{~s}$ (Figure 5(a)). Similarly, no MSL1 ${ }^{\text {R326Q }}$-GFP activity lasted longer than 20 s. In contrast, large proportions of MSL1 ${ }^{\text {D327G }}$-GFP and MSL1 ${ }^{\text {D327N-GFP activities }}$ lasted for more than $80 \mathrm{~s}(62.5 \%$ and $72.9 \%$, respectively) before final closure. Adding the R326Q mutation to these channels reduced the occurrence of extended activity to $48.4 \%$ and $42.1 \%$ of traces for $\mathrm{MSL}^{\mathrm{R} 326 \mathrm{Q}} \mathrm{D} 327 \mathrm{G}_{-} \mathrm{GFP}$ and

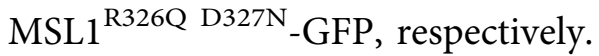

Open state dwell time was defined as the length of the initial pressure-gated channel opening before closure of any duration, as in [26,59]. As shown in Figure 5(b), the open state dwell time of MSL1-GFP was almost always (97\% of the time)
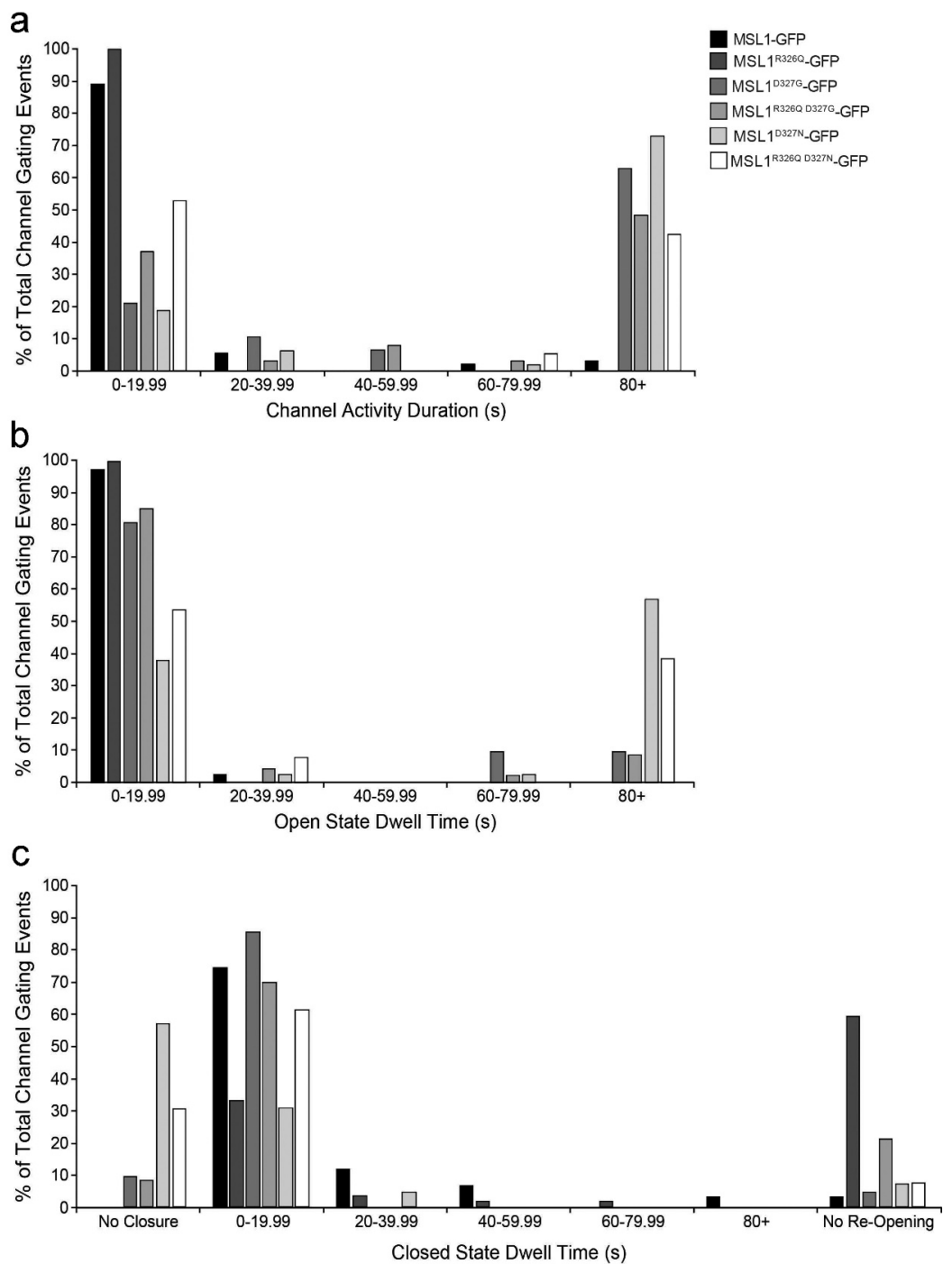

Figure 5. Effect of R326 and D327 mutations on channel kinetics of MSL1-GFP variants. Membrane potential was maintained at $-70 \mathrm{mV}$ and channel gating was triggered by either a $2 \mathrm{~s}$ or $4 \mathrm{~s}$ symmetric pressure ramp followed by monitoring of channel activity without additional pressure until $97.7 \mathrm{~s}$. (a) Channel activity duration, defined as the time from pressure-triggered gating to $\geq 5 \mathrm{~s}$ of channel closure. (b) Open state dwell time of initial pressure-triggered gating events. (c) Closed state dwell time, defined as the time from closure of the initial pressure-triggered gating event to the first subsequent gating event. Results from 19-97 traces from 9-10 patches $(A)$ and 13-59 traces from 7-10 patches $(b, c)$ per variant are shown. 
less than 20 s. However, we observed that MSL1 $^{\text {D327N }}$-GFP and MSL1 ${ }^{\text {R326Q D } 327 N}-$ GFP open states often persisted for much longer, in many cases $(57.1 \%$ and $30.7 \%$, respectively) remaining open until the end of the trace. MSL1 ${ }^{\mathrm{D} 327 \mathrm{G}}-\mathrm{GFP}$

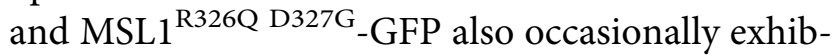
ited long open state dwell times (19\% and 10.6\%, respectively).

Closed state dwell time was defined as the time between the closure of the first pressure-gated channel and the second opening event. MSL1GFP gating events had relatively short closed state dwell times, with most traces (74.6\%) showing a second opening event within $20 \mathrm{~s}$ (Figure 5 (c)). For MSL1 ${ }^{\mathrm{R} 326 \mathrm{Q}}$-GFP most $(59.6 \%)$ channel closing events were never followed by a second opening. On the other hand, almost all (85.7\%)

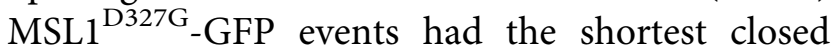
state dwell times, as did MSL1 ${ }^{\mathrm{R} 326 \mathrm{Q}}$ D327G - GFP (70.2\%). MSL1 ${ }^{\mathrm{D} 327 \mathrm{~N}_{-}}$GFP and $\mathrm{MSL1}^{\mathrm{R} 326 \mathrm{Q}} \mathrm{D} 327 \mathrm{~N}_{-}$ GFP frequently $(57.1 \%$ and $30.7 \%$, respectively) did not close at all during the assay.

To summarize, reducing the size and positive charge of the amino acid at position 326 decreased channel activity duration and open state dwell time while increasing closed state dwell time. Reducing the size and negative charge of the amino acid at position 327 caused the opposite effect, increasing channel activity duration and open state dwell time, and decreasing closed state dwell time. Finally, both double mutants showed intermediate phenotypes, suggesting that R326 and D327 in TM5 of MSL1 have opposite effects on closure efficiency.

\section{Some MSL1 variants have unstable open states}

Individual traces (Figure 6) at both $-60 \mathrm{mV}$ and $-120 \mathrm{mV}$ showed generally stable open states for

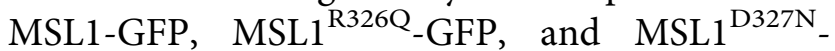
GFP. However, MSL1 ${ }^{\text {R326Q }}$ D327G_GFP, $\mathrm{MSL1}^{\mathrm{R} 326 \mathrm{Q} \text { D327N_GFP, and MSL1 }}{ }^{\mathrm{D} 327 \mathrm{G}}$-GFP were flickery (Figure 6). Flickery channel behavior is produced by rapid transitions between nonconducting, conducting, and subconducting states, and is thought to be indicative of an unstable open state $[59,60]$. Thus, the size and charge of residues at 326 and 327 are important to the stability of the MSL1 open state.

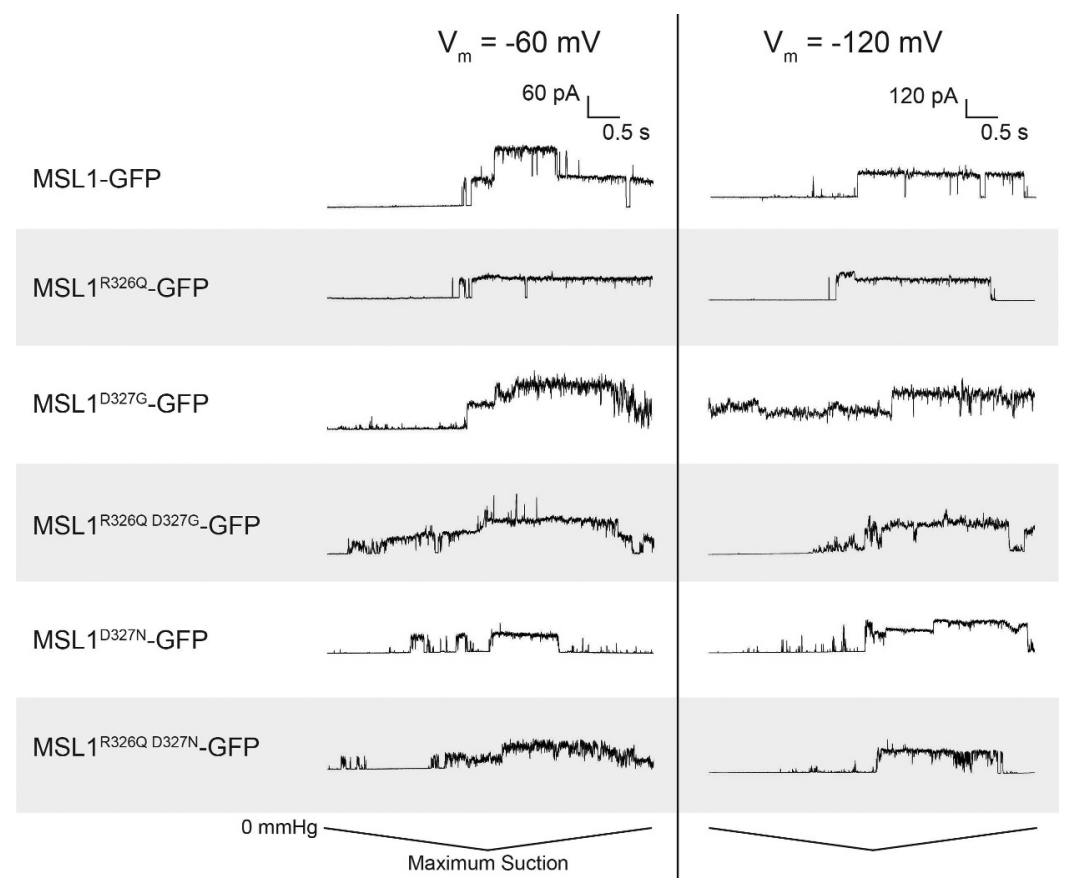

Figure 6. R326 and D327 influence open state stability of MSL1. Representative traces from inside-out excised patches showing pressure-activated gating events of MJF641(DE3) cells expressing the indicated constructs at two membrane potentials. Traces show current measurements taken during a $5 \mathrm{~s}$ symmetric negative pressure ramp, with the maximum amount of negative pressure (and therefore rate of pressure application) varying between traces. 


\section{R326 and D327 mutations alter the physiological function of MSL1 in E. coli}

Like EcMscS, MSL1 provides protection from hypo-osmotic shock to E. coli [31]. To determine the effects of R326 and D327 mutations on this osmoregulatory function, we examined the ability of E. coli MJF465(DE3) cells expressing GFPtagged MSL1 variants to survive hypoosmotic shock. MJF465(DE3) cells lack MscS, MscL, and $\mathrm{MscK}$ and therefore cannot survive severe hypoosmotic shock without expressing a functional MS ion channel [15]. In this assay, cells are grown in high salt citrate-phosphate media, channel expression is induced, then cells are either hypoosmotically shocked in water or transferred to the same high salt media. FRAG-1(DE3) cells, which contain all endogenous MS channels, survive, while MJF465(DE3) cells do not. MSL1-GFP, MSL1 ${ }^{\mathrm{R} 326 \mathrm{Q}}$-GFP, and MSL1 ${ }^{\mathrm{R} 326 \mathrm{Q}}$ D327G-GFP all conferred hypoosmotic shock survival rates comparable to that of FRAG-1 cells, suggesting that they all contribute to osmoregulation during hypoosmotic shock (Figure $7(\mathrm{a}, \mathrm{b})$ ). Survival rates

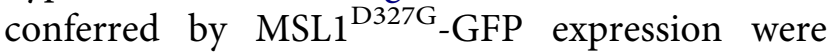
unusually variable and often higher for shocked cells than nonshocked cells (average survival rate of $160 \%$, Figure 7(a)). Cells expressing MSL1 $^{\text {D327N-GFP }}$ or MSL1 ${ }^{\text {R326Q D327N-GFP grew }}$ too slowly in citrate-phosphate media to be analyzed in this assay.

MSL1-GFP variants thus had a variety of effects on E. coli physiology that may be attributed to a combination of gating pressure (Figure 4), channel activity duration, open and closed state dwell times (Figure 5), and open state stability (Figure $6)$. The reduced duration of MSL1 ${ }^{\mathrm{R} 326 \mathrm{Q}_{-} \mathrm{GFP}}$ activity, and the increased gating pressure and activity

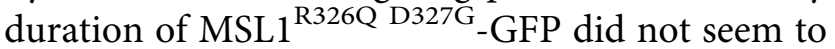
affect their function in E. coli cells during hypoosmotic shock. In contrast, we observed large variations in protection by MSL1 ${ }^{\mathrm{D} 327 \mathrm{G}}$-GFP between experiments, perhaps due to the combination of a lower gating threshold and extended activity duration. Based on our electrophysiological analysis, it is possible that the extended open dwell times and extended durations of MSL1 ${ }^{\text {D327N }}-$ GFP and $\mathrm{MSL1}^{\mathrm{R} 326 \mathrm{Q}} \mathrm{D}^{\mathrm{D} 27 \mathrm{~N}}-\mathrm{GFP}$ activity impaired cell growth. However, as both variants had higher gating pressures than MSL1-GFP, they do not fit classic gain-of-function characteristics [61].

\section{Discussion}

The Arabidopsis mitochondrial MS channel MSL1 contains a notable feature midway through its porelining TM5 helix: a kink formed by charged residues R326 and D327. In EcMscS, the pore-lining kink is proposed to play important roles in transitions between channel states $[18,19,23-26]$, but the residues that comprise it are nonpolar. To determine the role played by R326 and D327 in both distinct and shared characteristics of MSL1 and EcMscS, we created MSL1 variants in which the charges and size of R326 and D327 were altered, then evaluated their channel behavior and physiological function in E. coli. Mutations to R326 and D327 affected tension sensitivity, the duration of channel activity, open and closed state dwell times, and open state stability, indicating a role in modulating MSL1 channel state stabilities and transitions. These mutations did not appreciably affect stability, localization, conductance, nor rectification.

Based on open and closed state cryoEM structures, we have proposed that MSL1 opening is driven by membrane flattening and area expansion [37]. These forces drive the outward rotation and tilting of TM5 and the straightening of the kink that joins TM5a and TM5b during the MSL1 gating transition. The data presented here, summarized in Table 2, suggest that the charge and size of R326 and D327 side chains are important for the stability of the open state and for gating and closing transitions. Combining these results with cryoEM structures [37,38], we infer that in the closed state, charge-charge repulsion between R326 side chains on different monomers is finely balanced by charge-charge attractions between R326 and D327 within each monomer (Figure 1 $(b, d))$. In the open state, intra-monomeric attractive forces between R326 and D327 dominate and inter-monomeric repulsions lose strength, due to the increased distance between helices from different monomers and the shortened distance between R327 and D327 (Figure 1(c,e)). Below, we describe how our results can be explained by this "sweet spot" model. 

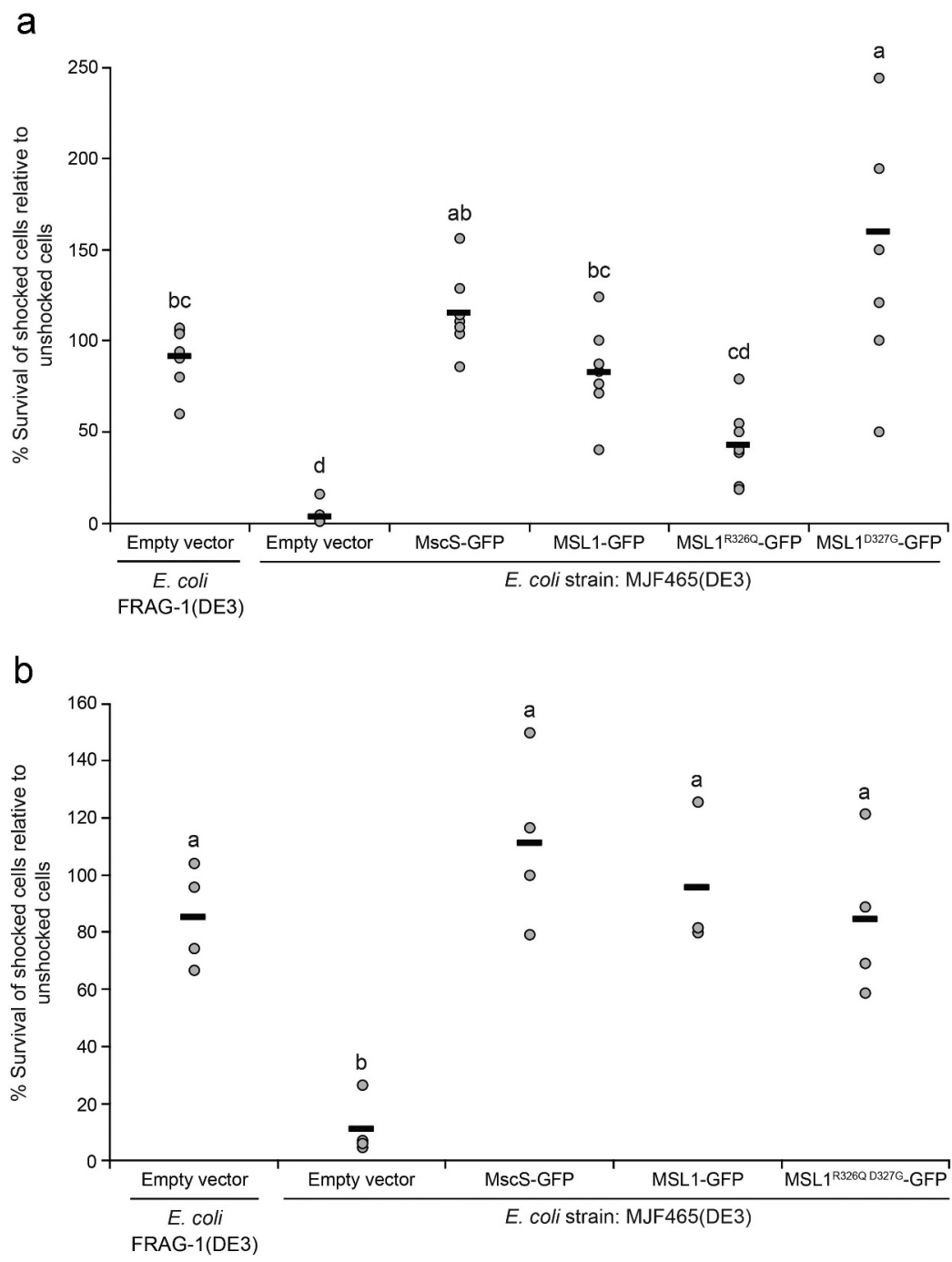

Figure 7. Some MSL1 variants protect $E$. coli strain MJF465(DE3) from hypoosmotic shock. Hypoosmotic shock survival rates of cells from the indicated strains relative to unshocked controls. Each circle represents the relative survival rate for an experiment and black bars indicate the average survival rate for all experiments. For each panel, statistical differences were evaluated using one-way ANOVA followed by a post-hoc Scheffe's test; different letters indicate samples that are statistically different $(p<0.05)$. One data point greater than two standard deviations beyond the sample average was excluded.

Table 2. Summary of GFP-tagged MSL1 variant properties. Conductance and gating pressure are presented relative to MSL1GFP measurements. ${ }^{\text {ns }}$ indicates differences from WT are not statistically significant.

\begin{tabular}{|c|c|c|c|c|}
\hline MSL1 Variant & Conductance & Gating Pressure & Open State Stability & Channel Activity Duration \\
\hline WT MSL1 & - & - & Stable & - \\
\hline MSL1 $1326 \mathrm{Q}$ & WT & $1.12 \mathrm{WT}^{\mathrm{ns}}$ & Stable & Short \\
\hline MSL1 ${ }^{\mathrm{D} 327 \mathrm{G}}$ & WT & $0.75 \mathrm{WT}^{\mathrm{ns}}$ & Flickery & Very Long \\
\hline MSL1 1 R326Q D327G & Low at $-60 \mathrm{mV}$ & $1.32 \mathrm{WT}$ & Slight Flicker & Long \\
\hline MSL1 1 ${ }^{\text {327N }}$ & WT & 1.39 WT & Stable & Very Long \\
\hline MSL1 ${ }^{\text {R326Q D327N }}$ & Low at $-60 \mathrm{mV}$ & $1.45 \mathrm{WT}$ & Slight Flicker & Long \\
\hline
\end{tabular}

The most dramatic effect of the lesions we created was on channel activity duration and open dwell time. The activity of $\mathrm{MSL1}^{\mathrm{D} 327 \mathrm{G}}-\mathrm{GFP}$, MSL1 ${ }^{\mathrm{R} 326 \mathrm{Q}}$ D327G-GFP, MSL1 ${ }^{\mathrm{D} 327 \mathrm{~N}}-\mathrm{GFP}$, and MSL1 ${ }^{\text {R326Q D327N }}$-GFP lasted far longer than that of MSL1-GFP (Figure 5(a)). All mutations to D327 caused extended channel activity durations (Figure 5(a)), and both MSL1 ${ }^{\mathrm{D} 327 \mathrm{~N}}-\mathrm{GFP}$ and $\mathrm{MSL}^{\mathrm{R} 326 \mathrm{Q}}$ D327N-GFP had longer open state and shorter closed state dwell times (Figure 5(b,c)). These 
results suggest that the charge-charge attraction between D327 and R326 facilitates closure. In contrast, MSL1 ${ }^{\text {R326Q }}$-GFP exhibited reduced channel activity duration (Figure 5(a)). According to our sweet spot model, the R326Q mutation on its own would also suffer from theloss of charge-charge attraction, but this effect is overshadowed by the loss of repulsion between R326 on different monomers in the closed state. Combining mutations in both residues leads to a channel where both attractive and repulsive forces are lost, and the channel activity duration and open state dwell time are intermediate between the two single mutants. A seemingly counterintuitive observation is that two channels (MSL1 ${ }^{\text {D327G-GFP and MSL1 }}{ }^{\text {R326Q }}$ D327G_GFP) have extended channel activity durations (Figure 5(a)) and are flickery (Figures 5,6). Perhaps these channels have both an unstable open state (hence the flickering) and an increased barrier to closing. Once they are stably closed, however, they stay closed until additional tension is applied.

Modest but statistically significant increases in gating pressure were observed with $\mathrm{MSL}^{\mathrm{R} 326 \mathrm{Q}}$

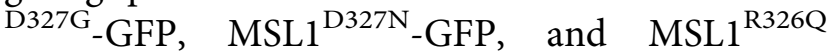
D327N_GFP (Figure 4). These results cannot be easily explained by the sweet spot model described above, but are reminiscent of the attractive chargecharge interactions between the transmembrane and cytoplasmic domains of EcMscS $[62,63]$. We also observed a mild decrease in the gating pressure of MSL1 ${ }^{\mathrm{D} 327 \mathrm{G}_{-}}$GFP (Figure 4). This may arise from destabilization of the closed state due to the loss of attractive charge-charge interactions and dominance of repulsive forces. The addition of the R326Q mutation in the MSL1 ${ }^{\mathrm{R} 326 \mathrm{Q}} \mathrm{D} 327 \mathrm{G}_{-}$ GFP may ameliorate this closed state repulsion, reversing the effects of the D327G mutation (Figure 4). However, due to the subtlety of the gating pressure changes we observed, other factors likely play a role that are beyond the scope of our model.

The results presented here establish the importance of two rings of oppositely charged neighboring residues in the channel pore in modulating channel kinetics and open state stability for the mitochondrial MS ion channel MSL1. Our data support a sweet spot model wherein attraction between oppositely charged residues on the same monomer and repulsion from identical residues on different monomers work together to facilitate opening and closing transitions as well as the stability of the closed and open states. Given their position at the pore-lining helix kink, a structural feature with demonstrated importance in $E c M s c S$ gating [25,26], this work provides a glimpse into how the same structural features can be composed of entirely distinct residues amongst members of the same MS channel family, creating different mechanisms of control. These results provide a starting point for future investigations into the fine-tuning of the MSL1 gating transition, as well as insight into the dynamic network of side-chain interactions contributing to MS channel behavior.

\section{Disclosure statement}

No potential conflict of interest was reported by the authors.

\section{Funding}

This work was supported by the Howard Hughes Medical Institute and the Simons Foundation [55108530]; the Spencer T. and Ann W. Olin Fellowship for Women in Graduate Study; William H. Danforth Plant Sciences Fellowship.

\section{ORCID}

Angela M. Schlegel (D) http://orcid.org/0000-0001-5253-5769

\section{References}

[1] Fruleux A, Verger S, Boudaoud A. Feeling stressed or strained? A biophysical model for cell wall mechanosensing in plants. Front Plant Sci. 2019;10. DOI:10.3389/fpls.2019.00757

[2] Persat A, Nadell CD, Kim MK, et al. The mechanical world of bacteria. Cell. 2015;161(5):988-997.

[3] Yang C, Zhang X, Guo Y, et al. Mechanical dynamics in live cells and fluorescence-based force/tension sensors. Biochim Biophys Acta. 2015;1853 (8):1889-1904.

[4] Hamilton ES, Schlegel AM, Haswell ES. United in diversity: mechanosensitive ion channels in plants. Annu Rev Plant Biol. 2015;66(1):8.1-8.25.

[5] Kloda A, Martinac B. Structural and functional differences between two homologous mechanosensitive channels of Methanococcus jannaschii. Embo J. 2001;20(8):1888-1896. 
[6] Kung C, Martinac B, Sukharev S. Mechanosensitive channels in microbes. Annu Rev Microbiol. 2010;64:313-329.

[7] Ranade SS, Syeda R, Patapoutian A. Mechanically activated ion channels. Neuron. 2015;87(6):1162-1179.

[8] Cox CD, Bavi N, Martinac B. Biophysical principles of ion-channel-mediated mechanosensory transduction. Cell Rep. 2019;29(1):1-12.

[9] Haswell ES. MscS-Like proteins in plants. Curr Top Membr. 2007;58:329-359. Elsevier.

[10] Malcolm HR, Maurer JA. The mechanosensitive channel of small conductance (MscS) superfamily: not just mechanosensitive channels anymore. ChemBioChem. 2012;13(14):2037-2043.

[11] Pivetti CD, Yen M-R, Miller S, et al. Two families of mechanosensitive channel proteins. MMBR. 2003;67 (1):66-85.

[12] Bialecka-Fornal M, Lee HJ, Phillips R. The rate of osmotic downshock determines the survival probability of bacterial mechanosensitive channel mutants. J Bacteriol. 2015;197(1):231-237.

[13] Boer M, Anishkin A, Sukharev S. Adaptive MscS gating in the osmotic permeability response in E. coli: the question of time. Biochemistry. 2011;50 (19):4087-4096.

[14] Buda R, Liu Y, Yang J, et al. Dynamics of Escherichia coli 's passive response to a sudden decrease in external osmolarity. PNAS. 2016;113(40):E5838-E5846.

[15] Levina N. Protection of Escherichia coli cells against extreme turgor by activation of $\mathrm{MscS}$ and $\mathrm{MscL}$ mechanosensitive channels: identification of genes required for MscS activity. Embo J. 1999;18 (7):1730-1737.

[16] Rojas E, Theriot JA, Huang KC. Response of Escherichia coli growth rate to osmotic shock. PNAS. 2014;111(21):7807-7812.

[17] Bass RB, Strop P, Barclay M, et al. Crystal Structure of Escherichia coli MscS, a voltage-modulated and mechanosensitive channel. Science. 2002;298 (5598):1582-1587.

[18] Lai JY, Poon YS, Kaiser JT, et al. Open and shut: crystal structures of the dodecylmaltoside solubilized mechanosensitive channel of small conductance from Escherichia coli and Helicobacter pylori at $4.4 \AA$ and $4.1 \AA$ resolutions. Protein Sci. 2013;22 (4):502-509.

[19] Pliotas C, Dahl ACE, Rasmussen T, et al. The role of lipids in mechanosensation. Nat Struct Mol Biol. 2015;22(12):991-998.

[20] Rasmussen T, Flegler VJ, Rasmussen A, et al. Structure of the mechanosensitive channel MscS embedded in the membrane bilayer. J Mol Biol. 2019;431 (17):3081-3090.

[21] Reddy B, Bavi N, Lu A, et al. Molecular basis of force-from-lipids gating in the mechanosensitive channel MscS. eLife. 2019;8:e50486.
[22] Steinbacher S, Bass R, Strop P, et al. Structures of the prokaryotic mechanosensitive channels $\mathrm{MscL}$ and MscS. Curr Top Membr. 2007;58:1-24. Elsevier.

[23] Wang W, Black SS, Edwards MD, et al. The structure of an open form of an E. coli mechanosensitive channel at $\quad 3.45$ a resolution. Science. 2008;321 (5893):1179-1183.

[24] Vásquez V, Sotomayor M, Cordero-Morales J, et al. A structural mechanism for $\mathrm{MscS}$ gating in lipid bilayers. Science. 2008;321(5893):1210-1214.

[25] Akitake B, Anishkin A, Liu N, et al. Straightening and sequential buckling of the pore-lining helices define the gating cycle of MscS. Nat Struct Mol Biol. 2007;14 (12):1141-1149.

[26] Edwards MD, Bartlett W, Booth IR. Pore mutations of the Escherichia coli MscS channel affect desensitization but not ionic preference. Biophys J. 2008;94 (8):3003-3013.

[27] Basu D, Haswell ES. Plant mechanosensitive ion channels: an ocean of possibilities. Curr Opin Plant Biol. 2017;40:43-48.

[28] Hamilton ES, Jensen GS, Maksaev G, et al. Mechanosensitive channel MSL8 regulates osmotic forces during pollen hydration and germination. Science. 2015;350(6259):438-441.

[29] Haswell ES, Peyronnet R, Barbier-Brygoo H, et al. Two MscS homologs provide mechanosensitive channel activities in the Arabidopsis root. Curr Biol. 2008;18 (10):730-734.

[30] Haswell ES, Meyerowitz EM. MscS-like proteins control plastid size and shape in Arabidopsis thaliana. Curr Biol. 2006;16(1):1-11.

[31] Lee CP, Maksaev G, Jensen GS, et al. MSL1 is a mechanosensitive ion channel that dissipates mitochondrial membrane potential and maintains redox homeostasis in mitochondria during abiotic stress. Plant J. 2016;88(5):809-825.

[32] Hamilton ES, Haswell ES. The tension-sensitive ion transport activity of MSL8 is critical for its function in pollen hydration and germination. Plant Cell Physiol. 2017;58(7):1222-1237.

[33] Maksaev G, Haswell E. MscS-Like10 is a stretch-activated ion channel from Arabidopsis thaliana with a preference for anions. PNAS. 2012;109 (46):19015-19020.

[34] Veley KM, Marshburn S, Clure CE, et al. Mechanosensitive channels protect plastids from hypoosmotic stress during normal plant growth. Curr Biol. 2013;22(5):408-413.

[35] Maksaev G, Shoots JM, Ohri S, et al. Nonpolar residues in the presumptive pore-lining helix of mechanosensitive channel MSL10 influence channel behavior and establish a nonconducting function. Plant Direct. 2018;2(6):e00059.

[36] Veley KM, Maksaev G, Frick EM, et al. Arabidopsis MSL10 has a regulated cell death signaling activity that 
is separable from its mechanosensitive ion channel activity. Plant Cell. 2014;26(7):3115-3131.

[37] Deng Z, Maksaev G, Schlegel AM, et al. Structural mechanism for gating of a eukaryotic mechanosensitive channel of small conductance. Nat Commun. 2020;11 (1):3690.

[38] $\mathrm{Li} \mathrm{Y,} \mathrm{Hu} \mathrm{Y,} \mathrm{Wang} \mathrm{J,} \mathrm{et} \mathrm{al.} \mathrm{Structural} \mathrm{insights} \mathrm{into}$ a plant mechanosensitive ion channel MSL1. Cell Rep. 2020;30(13):4518-4527.e3.

[39] Sukharev S. Purification of the small mechanosensitive channel of Escherichia coli (MscS): the subunit structure, conduction, and gating characteristics in liposomes. Biophys J. 2002;83(1):290-298.

[40] Anishkin A, Akitake B, Kamaraju K, et al. Hydration properties of mechanosensitive channel pores define the energetics of gating. J Phys Condens Matter. 2010;22(45):454120.

[41] Belyy V, Anishkin A, Kamaraju K, et al. The tensiontransmitting "clutch" in the mechanosensitive channel MscS. Nat Struct Mol Biol. 2010;17(4):451-458.

[42] Sukharev S, Akitake B, Anishkin A. The bacterial mechanosensitive channel MscS: emerging principles of gating and modulation. Curr Top Membr. 2007;58:235-267. Academic Press.

[43] Rowe I, Elahi M, Huq A, et al. The mechanoelectrical response of the cytoplasmic membrane of Vibrio cholerae. J Gen Physiol. 2013;142(1):75-85.

[44] Nakayama Y, Fujiu K, Sokabe M, et al. Molecular and electrophysiological characterization of a mechanosensitive channel expressed in the chloroplasts of Chlamydomonas. PNAS. 2007;104(14):5883-5888.

[45] Kloda A, Martinac B. Molecular Identification of a mechanosensitive channel in Archaea. Biophys J. 2001;80(1):229-240.

[46] Nakayama Y, Yoshimura K, Iida $H$. Electrophysiological characterization of the mechanosensitive channel MscCG in Corynebacterium glutamicum. Biophys J. 2013;105(6):1366-1375.

[47] Petrov E, Palanivelu D, Constantine M, et al. Patchclamp characterization of the MscS-like mechanosensitive channel from silicibacter pomeroyi. Biophys J. 2013;104(7):1426-1434.

[48] Li L, Liu K, Hu Y, et al. Single mutations convert an outward $\mathrm{K}+$ channel into an inward $\mathrm{K}+$ channel. PNAS. 2008;105(8):2871-2876.

[49] Epstein W, Kim BS. Potassium transport loci in Escherichia coli K-12. J Bacteriol. 1971;108(2):639-644.

[50] Edwards MD, Black S, Rasmussen T, et al. Characterization of three novel mechanosensitive channel activities in Escherichia coli. Channels. 2012;6 (4):272-281.

[51] Schlegel AM, Haswell ES. Analyzing plant mechanosensitive ion channels expressed in giant $E$. coli spheroplasts by single-channel patch-clamp electrophysiology. In Methods in Cell Biology. Elsevier; 2020. p. S0091679X20300133. DOI:10.1016/bs.mcb.2020.02.007

[52] Bartlett JL, Levin G, Blount P. An in vivo assay identifies changes in residue accessibility on mechanosensitive channel gating. PNAS. 2004;101(27): 10161-10165.

[53] Romantsov T, Battle AR, Hendel JL, et al. Protein localization in Escherichia coli cells: comparison of the cytoplasmic membrane proteins ProP, LacY, ProW, AqpZ, MscS, and MscL. J Bacteriol. 2010;192 (4):912-924.

[54] van den Berg J, Galbiati H, Rasmussen A, et al. On the mobility, membrane location and functionality of mechanosensitive channels in Escherichia coli. Sci Rep. 2016;6(1):1-11.

[55] Okada K, Moe PC, Blount P. Functional design of bacterial mechanosensitive channels comparisons and contrasts illuminated by random mutagenesis. J Biol Chem. 2002;277(31):27682-27688.

[56] Gerencser AA, Chinopoulos C, Birket MJ, et al. Quantitative measurement of mitochondrial membrane potential in cultured cells: calcium-induced deand hyperpolarization of neuronal mitochondria. J Physiol. 2012;590(12):2845-2871.

[57] Schwarzländer M, Logan DC, Johnston IG, et al. Pulsing of membrane potential in individual mitochondria: a stress-induced mechanism to regulate respiratory bioenergetics in Arabidopsis. Plant Cell. 2012;24 (3):1188-1201.

[58] Blount P, Sukharev SI, Schroeder MJ, et al. Single residue substitutions that change the gating properties of a mechanosensitive channel in Escherichia coli. PNAS. 1996;93(21):11652-11657.

[59] Malcolm HR and Blount P. Mutations in a conserved domain of $E$. coli $\mathrm{MscS}$ to the most conserved superfamily residue leads to kinetic changes. PLoS ONE. 2015;10(9):e0136756.

[60] Rasmussen A, Rasmussen T, Edwards MD, et al. The role of tryptophan residues in the function and stability of the mechanosensitive channel MscS from Escherichia coli. Biochemistry. 2007;46(38): 10899-10908.

[61] Blount P, Schroeder MJ, Kung C. Mutations in a bacterial mechanosensitive channel change the cellular response to osmotic stress. J Biol Chem. 1997;272 (51):32150-32157.

[62] Machiyama H, Tatsumi H, Sokabe M. Structural changes in the cytoplasmic domain of the mechanosensitive channel MscS during opening. Biophys J. 2009;97(4):1048-1057.

[63] Nomura T, Sokabe M, Yoshimura K. Interaction between the cytoplasmic and transmembrane domains of the mechanosensitive channel MscS. Biophys J. 2008;94(5):1638-1645. 